\title{
Polyaniline Thin Film Prepared by Electrochemical Polymerization Method
}

\author{
Fatiha Saouti $^{\text {1,* (D) , Said Belaaouad }}{ }^{1}$ (D), Abdelouahed Cherqaoui ${ }^{1}$ (D), Youssef Naimi ${ }^{1}$ (D) \\ 1 Laboratory of Physical Chemistry of Materials, FSBM, Hassan II University of Casablanca,; \\ saoutifatiha2@gmail.com(F.S); $\quad$ sbelaaouad@yahoo.fr $\quad$ (S.B.); $\quad$ cherqaoui.abdel1@gmail.com \\ (A.C.);youssef.naimi@univh2c.ma (Y.N.); \\ * Correspondence: saoutifatiha2@gmail.com(F.S);
}

Scopus Author ID 57221785809

Received: 5.07.2021; Revised: 20.08.2021; Accepted: 23.08.2021; Published: 19.10.2021

\begin{abstract}
Polyaniline (PANI) slim film was set up by electrochemical polymerization strategy at room temperature in a standard three-electrode cell from $(0.1 \mathrm{M})$ aniline monomer and $(0,5 \mathrm{M})$ from Sulfuric acid in the presence of distilled water. The development of PANI film was portrayed by Voltammetric studies, SEM, XRD, and FTIR. Voltammetric studies were performed in $0.5 \mathrm{M}$ acidic aqueous solutions using H2SO4. The XRD design demonstrated that the diffraction top at $2 \theta=\left(30^{\circ}\right)$. The FTIR spectroscopy spectra give particular and unmistakable bonds at 3500, 1572.52, 1302.53, 831.98, and $592.85 \mathrm{~cm}^{-1}$.
\end{abstract}

Keywords: polyaniline; electrochemical; X-ray diffraction; infrared vibration; SEM; voltammetric studies.

(C) 2021 by the authors. This article is an open-access article distributed under the terms and conditions of the Creative Commons Attribution (CC BY) license (https://creativecommons.org/licenses/by/4.0/).

\section{Introduction}

Aniline is an oily liquid, colorless when freshly distilled but tending to turn brown under the action of light. Polyaniline is a very promising polymer with a broad spectrum of applications thanks to its inherent properties. In addition to the relatively manageable and feasible procedures for its synthesis, it exhibits high conductivity and acid-base properties in an aqueous solution. Its doping-dedoping is characterized by simple and reversible chemical reactions. In addition, it is thermally stable and does not have a negative impact on the environment[1].

Synthesis from nitrobenzene:

$$
2 \mathrm{C}_{6} \mathrm{H}_{5} \mathrm{NO}_{3}+8 \mathrm{H}_{2} \rightarrow 2 \mathrm{C}_{6} \mathrm{H}_{5} \mathrm{NH}_{2}+6 \mathrm{H}_{2} \mathrm{O}
$$

However, polyaniline is insoluble in most of the solvents used and has poor physical and mechanical properties. But thanks to its remarkable electrical and optical properties, polyaniline is widely used in the development of rechargeable batteries, OLEDS, organic transistors, conductive paints and adhesives, foam for thermal insulation of astronautical spacecraft, a product of coating, OLCD, etc. [2].

Among the various oxidation states of polyaniline, emeraldine salt (ES) is the only one with electrical conductivity. However, emeraldine base (EB) can be converted to emeraldine salt (ES), and vice versa, by protonation/deprotonation with an acid/base [3]. 
Polyaniline represents the material of choice for contemporary and future electronics technology due to its easy production, controllable and reversible electrical and electronic properties through oxidation and protonation (non-redox doping) [4].

The alternating bonds in the long polyaniline chain make it extremely difficult to handle, infusible, and practically insoluble in common organic solvents[5].

The radical nature of the anilinium makes it possible to catalyze the polymerization of the aniline monomers oxidized to polyaniline, the anilinium also plays the role of the reaction intermediate in the polymerization of the aniline and its derivatives [6,7], and in order to obtain new conductive polyaniline forms, the aniline copolymers were prepared in such a way that there were variations in the angle of twist between the adjacent phenyl rings of the polymer, as well as the modification chemical reaction of aniline by substitutions located on the nitrogen atom or in the benzoide or quinoid cycles [8].

Let us detail some methods of polyaniline synthesis, concerning its electrosynthesis, and we can use potentiostatic or galvanostatic electrochemical methods, the oxidation of aniline by inert electrodes such as stainless steel, platinum, gold, different types of carbon (vitreous or pyrolytic graphite), and glass coated with metal oxides, metal electrodes modified by a carbon foot and electron acceptor carbon nanotubes[9,10].

In this paper, Polyaniline thin film will be prepared by electrochemical polymerization method and characterized by Cyclic voltammetry, SEM, DRX, RAMAN, and FTIR.

\section{Materials and Methods}

\subsection{Materials.}

Aniline monomer was acquired from Merck, vacuum distilled. In all electrosynthesis tests, polymerization solutions were prepared to utilize twice distilled water. The physical characteristics of aniline are given in Table 1:

Table 1. Physical characteristics of aniline.

\begin{tabular}{|c|c|c|c|c|c|c|}
\hline logPow & $\eta$ (Viscosity) & $\mathbf{T}_{\text {ebu }}\left({ }^{\circ} \mathbf{C}\right)$ & d & $\mathbf{P}_{\mathrm{s}}\left(\mathrm{hPa}\right.$ at $\left.20^{\circ} \mathrm{C}\right)$ & $\mathrm{M}(\mathrm{g} / \mathrm{mol})$ & $\mathbf{T}_{\text {fus }}\left({ }^{\circ} \mathbf{C}\right)$ \\
\hline 0.9 & $4.4 \mathrm{mPa} . \mathrm{S}$ & 184 & 1.022 & 0.4 & 93.13 & $-6.2^{\circ} \mathrm{C}$ \\
\hline
\end{tabular}

The polymerization solutions were $0.5 \mathrm{M}$ aqueous $\mathrm{H}_{2} \mathrm{SO}_{4}$ solutions (provided by Merck). The polyaniline (PAni) films were covered in aqueous $0.5 \mathrm{M} \mathrm{H}_{2} \mathrm{SO}_{4}$ containing $0.1 \mathrm{M}$ aniline with polarization in the potential rate between -0.2 and $1.2 \mathrm{~V}$ versus $\mathrm{Ag} / \mathrm{AgCl}$ at $50 \mathrm{mV} / \mathrm{s} \mathrm{scan}$ rate. Distilled and deionized water were utilized.

\subsection{Synthesis.}

The electrochemical synthesis and characterization of polyaniline were carried out at room temperature in a standard three-electrode cell [11]. The working electrode was a glassy carbon, and the counter electrode was platinum. As a reference electrode, we used a saturated $\mathrm{Ag} / \mathrm{AgCl}$ reference electrode. Before each electrochemical synthesis, the working electrode was carefully polished with abrasive paper and then washed with distilled water. Aniline was used after distillation. Cyclic voltammetry control was provided by a Voltalab connected with the cell. The polymer film of aniline was deposited from 0.5 acidic aqueous media containing0.1 $\mathrm{M}$ aniline by voltammetric sweep between $-0.2 \mathrm{~V}$ and $1.2 \mathrm{~V}(\mathrm{Ag} / \mathrm{AgCl})$, at 50 
$\mathrm{mV} / \mathrm{s}^{-1}$. The sweep was stopped after 15 cycles, and the working electrode covered by polymer film was removed from the monomer solution and washed with distilled water.

\subsection{Voltammetry cyclic.}

Voltammetric studies were performed in $0.5 \mathrm{M}$ acidic aqueous solutions using $\mathrm{H}_{2} \mathrm{SO}_{4}$. Voltalab model PGZ100 (France) was used for cyclic voltammetry analysis and electrochemical measurement.

\subsection{Fourier transform infrared spectroscopy.}

The electronic structures of polymer films of aniline were determined by Fourier transform infrared spectroscopy (FTIR) spectra were obtained on a Brukertensor-27 FTIR spectrometer, using samples dispersed in spectroscopically pure $\mathrm{KBr}$ pellets.

\subsection{X-ray diffraction.}

The sample was analyzed by X-ray diffraction using Bruker D8 Venture Super DUO diffractometer with PHOTON100 CMOS area-detector using $\operatorname{MoK} \alpha$ radiation $(\lambda=0.71073 \mathrm{~A})$ monochromated by the graphite.

\subsection{Raman spectroscopy.}

The Raman spectrum was recorded from $100-3500 \mathrm{~cm} 1$ with a Raman dispersive microscope DXR2 (Thermo scientific).

\subsection{Scanning electron microscope.}

The morphological characteristic of the polyaniline was characterized by scanning electron microscopy (SEM) SH 4000M.

\section{Results and Discussion}

\subsection{Voltammetry cyclic.}

The inset of Figure 1 is the cyclic voltammograms (CV) for pure polyaniline $0.5 \mathrm{M}$ $\mathrm{H}_{2} \mathrm{SO}_{4}$. The voltammogram is similar to that obtained by G. Wu et al. [12]. The observation of the $\mathrm{J}=\mathrm{f}(\mathrm{E})$ curve of cycle 1 (corresponding to the first sweep of cycle 1 potential) shows an abrupt increase of the current towards $1.18 \mathrm{~V} / \mathrm{EAg} / \mathrm{AgCl}$, which corresponds to the oxidation of a species on the surface of the glassy carbon electrode. Note that this anodic peak is the only one that does not correspond to any cathodic peak on the voltammogram. This suggests that it is associated with the oxidation of aniline to form polyaniline and that this reaction is irreversible. More precisely, it is the oxidation of the acid-soluble form of aniline, that is, anilinium. Mu et al. [13] were interested in this reaction and wanted to determine whether the reaction involved free radicals or cation radicals. They demonstrated that the first step in forming polyaniline corresponds to the oxidation of anilinium cations to cation radicals (Figure $1)$. 


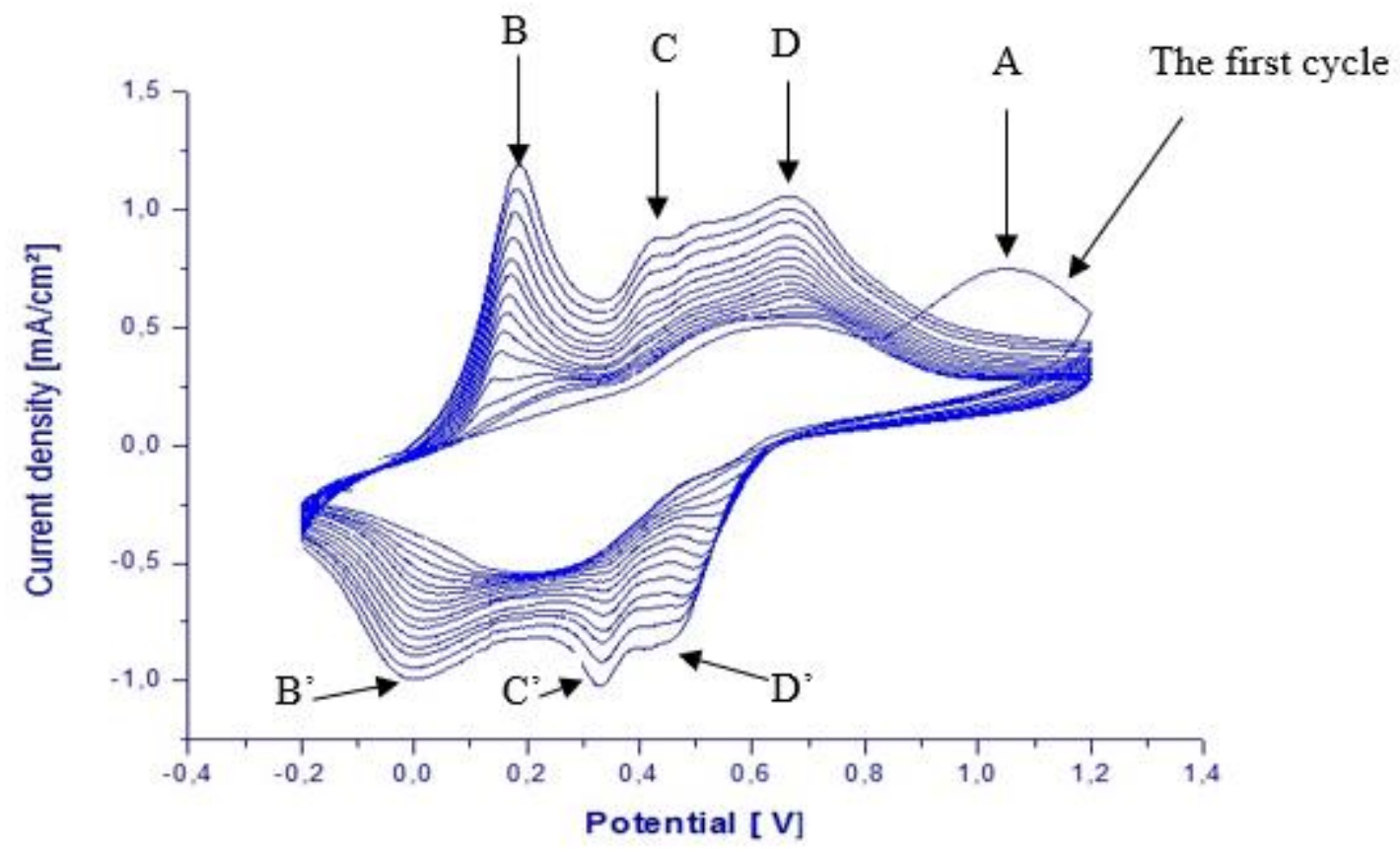

Figure 1. Cyclic voltammogram (CV) curves of polyaniline prepared in an aqueous solution of $0.1 \mathrm{M}$ monomer aniline and $0.5 \mathrm{M} \mathrm{H} 2 \mathrm{SO} 4,50 \mathrm{mV} / \mathrm{s}^{-1}$.

In cycles following the first, the anodic current of peak A decreases due to polymer formation on the surface and leads to a decrease in monomer oxidation in favor of continuously increasing signal intensity of the formation peaks. These peaks are characteristic of polymer growth on the surface of the carbon electrode. Thus, as the polymerization proceeds, the intensity increases with the thickness of the polymer film.

For example, the reactions observed on the surface of the glassy carbon electrode correspond to the different oxidation states of the polyaniline :

Peak B: the oxidation of leucoemeraldine to emeraldine,

Peak B': the reduction of emeraldine to leucoemeraldine,

Peak D: the oxidation of emeraldine to pernigraniline,

$\mathrm{D}^{\prime}$ peak: the reduction of pernigraniline to emeraldine,

The oxidation and reduction currents in peaks $\mathrm{C}$ and $\mathrm{C}^{\prime}$ correspond to the oxidation of hydroquinone to benzoquinone and the reversible reduction reaction of polyaniline degradation products.

\subsubsection{Effect of the rate of change in potential.}

The effect of potential sweep rate was studied for values of $25,50,75$, and $100 \mathrm{mV} / \mathrm{s}$ to characterize the processes involved in the electrooxidation of PANI.

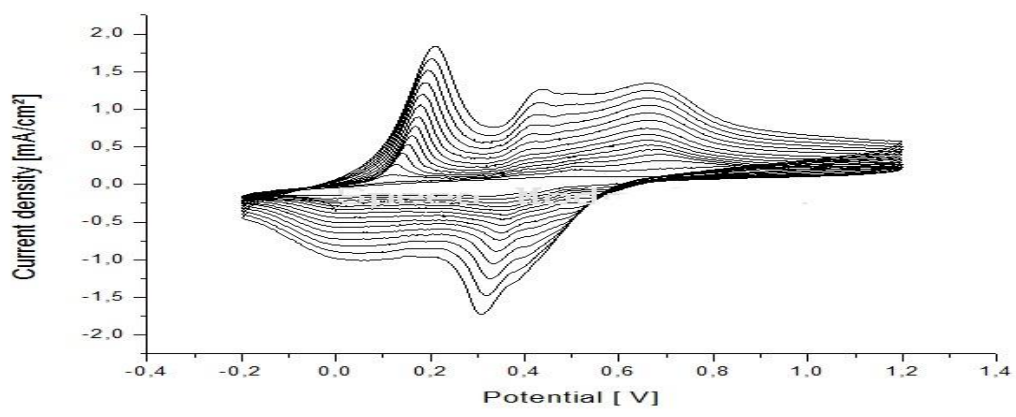

Figure 2. CV curves of polyaniline, $25 \mathrm{mV} / \mathrm{s}^{-1}$. 


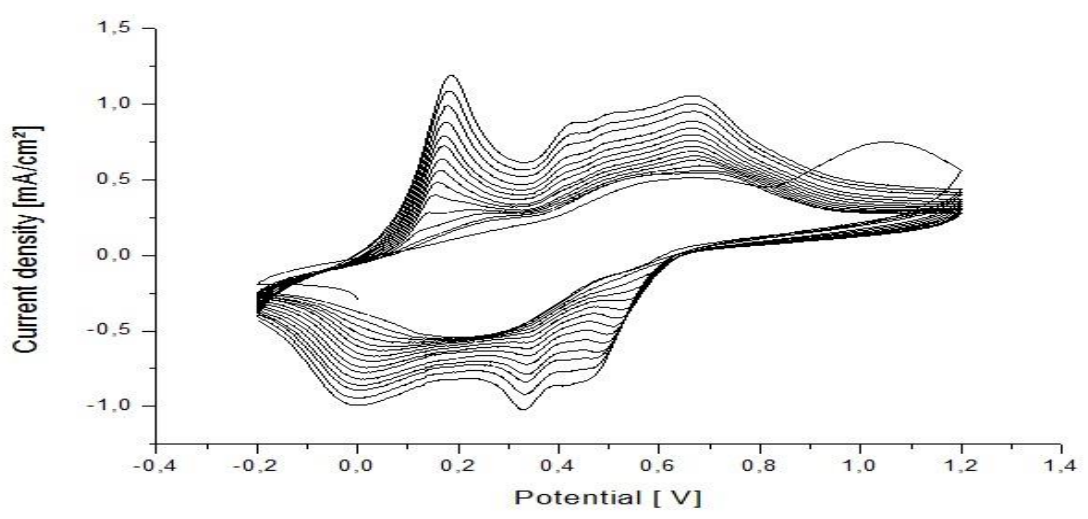

Figure 3. CV curves of polyaniline, $50 \mathrm{mV} / \mathrm{s}^{-1}$.

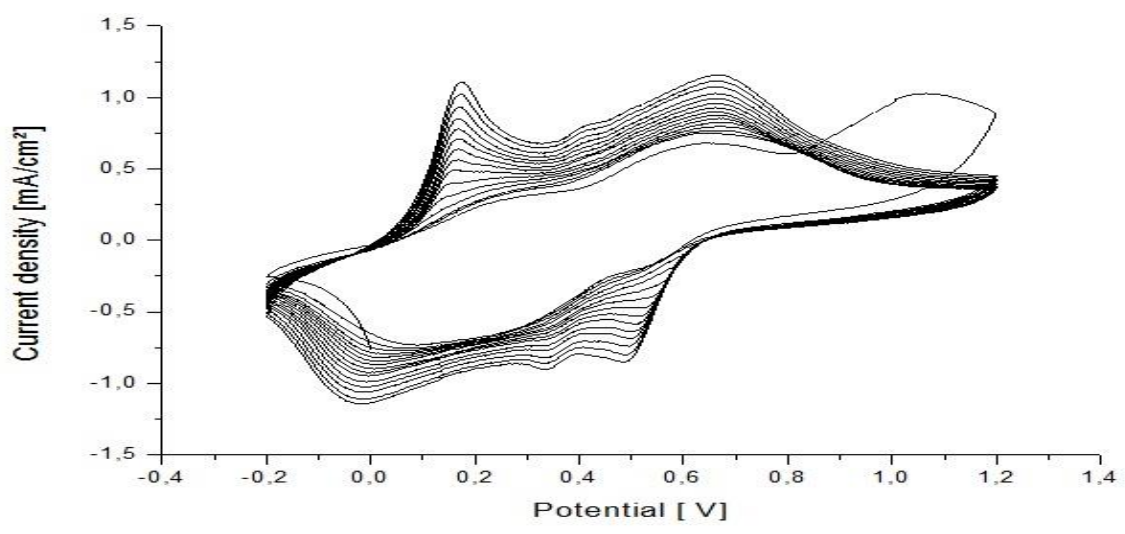

Figure 4. $\mathrm{CV}$ curves of polyaniline, $75 \mathrm{mV} / \mathrm{s}^{-1}$.

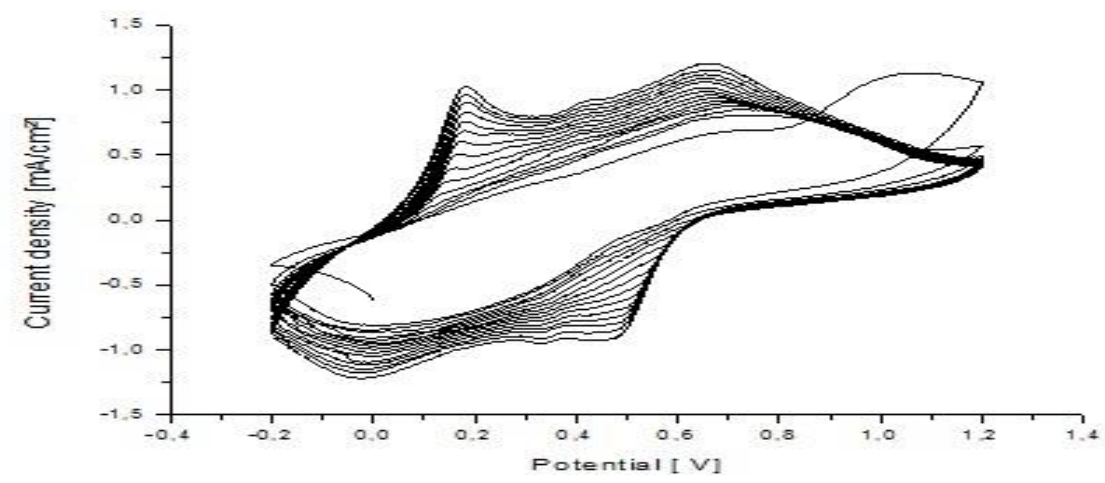

Figure 5.CV curves of polyaniline, $100 \mathrm{mV} / \mathrm{s}^{-1}$.

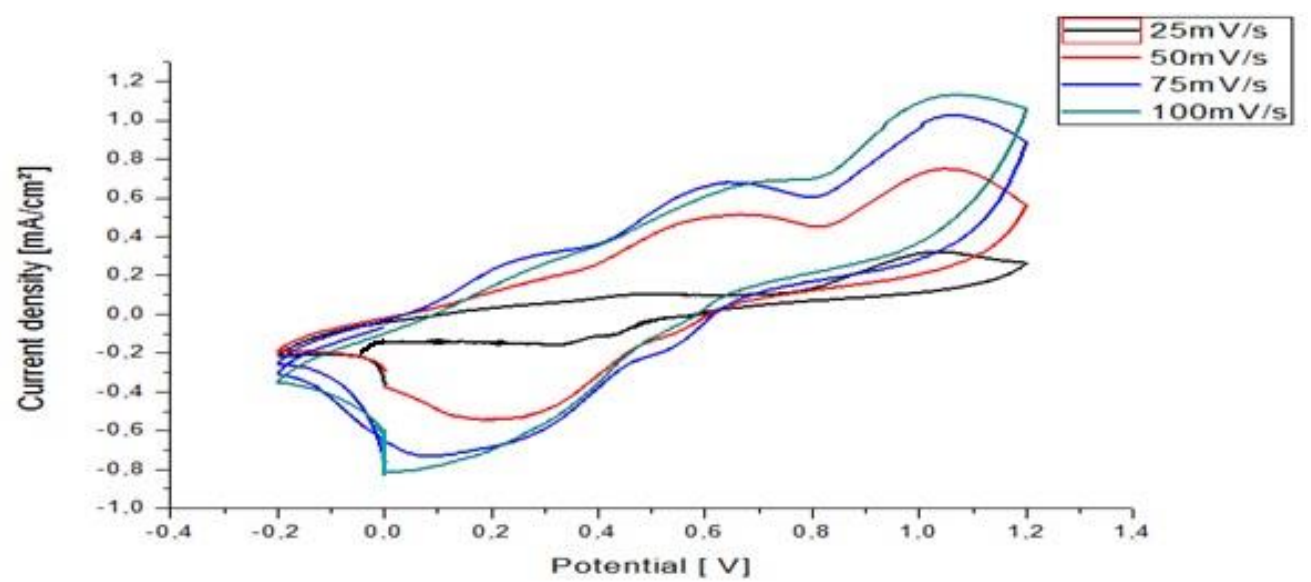

Figure 6. Voltammograms recorded in the potential range $(-0.2 ; 1.2 \mathrm{~V} / \mathrm{s})$ for these different values of the potential scanning rate. 
The values of the peak potentials (Epa), as well as the values of the anode peak currents (Ipa) for the different potential scanning speeds, are shown in Table 2.

Table 2. Electrochemical parameters of Polyaniline in $\mathrm{H}_{2} \mathrm{SO}_{4}$ acid solution at different potential scanning rates (GC electrode).

\begin{tabular}{l|l|l|l|l} 
Scanning rate $(\mathrm{mV} / \mathrm{s})$ & 25 & 50 & 75 & 100 \\
\hline $\begin{array}{l}\text { Potentials anodic peak } \\
(\mathrm{mV} / \mathrm{Ag} / \mathrm{AgCl})\end{array}$ & 1 & 1 & 1 & 1 \\
\hline $\begin{array}{l}\text { Currents anodic peak } \\
\left(\mathrm{mA} / \mathrm{cm}^{2}\right)\end{array}$ & 0.33 & 0.75 & 1.03 & 1.13
\end{tabular}

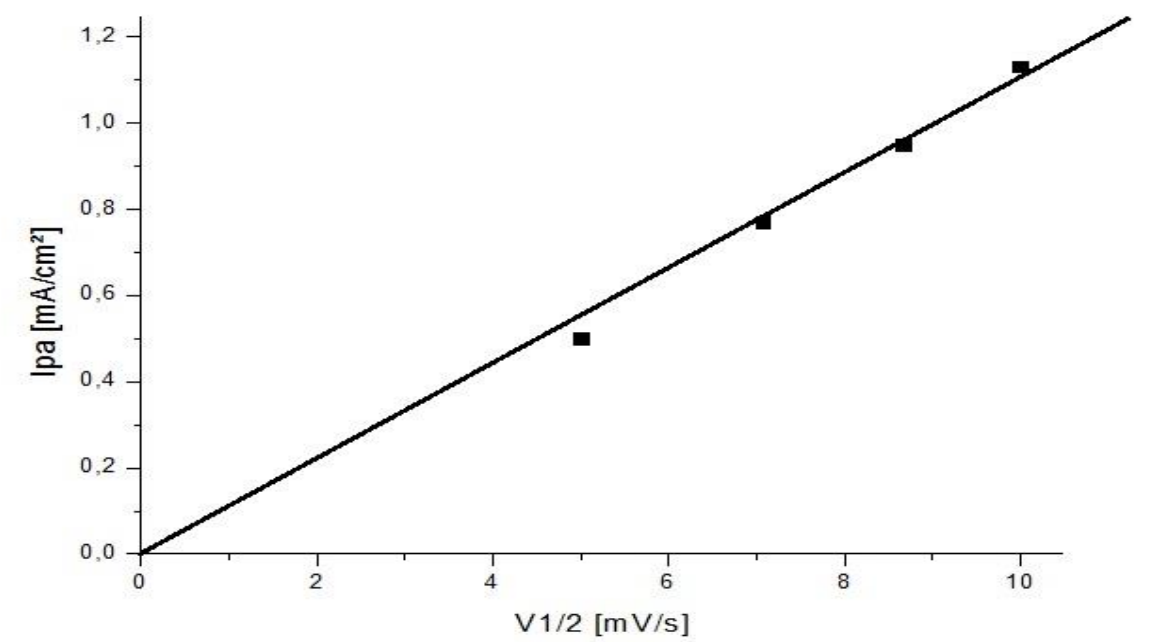

Figure 7. Variation of anode peak currents as a function of the square root of the scanning rate.

The oxidation peak potential (Epa) is independent of the potential scan rate. So we are in the presence of a fast reaction. The variation of the anodic peak currents is best expressed by plotting the variation of the anodic peak currents as a function of the square root of the scan rate (Figure 7).

The variation of the oxidation peak currents as a function of the square root of the scan speed of potential $I p=f(v 1 / 2)$ is a straight line. This shows that the electrochemical reaction is controlled by diffusion. The value of the slope is $0.155 \mathrm{~mA} \mathrm{~s} 1 / 2 \mathrm{mV}-1 / 2$.

$$
\mathrm{Ip}=\left[0,446 \cdot \mathrm{A} \cdot \mathrm{R} \cdot \mathrm{T}^{\frac{1}{2}} \cdot \mathrm{F}^{\frac{3}{2}} \cdot \mathrm{D}_{\mathrm{R}}^{\frac{1}{2}} \cdot \mathrm{C}_{\mathrm{R}}\right] \mathrm{V}^{1 / 2}
$$

We can conclude that the oxidation reaction of polyaniline on glassy carbon in $0.5 \mathrm{M}$ sulfuric acid is fast and diffusion-controlled.

\subsection{Morphology of PANI.}

Morphology of conducting polymer layers kept on a glassy carbon substrate was first characterized utilizing a scanning electron microscopy technique.

Figure 8 shows the SEM morphology of PANI film acquired in a solution containing $0.1 \mathrm{M}$ aniline and $0.5 \mathrm{M} \mathrm{H}_{2} \mathrm{SO}_{4}$ kept onto GC. From this figure, the spread PANI fibrils as noticed, and the strands are ordinary and uniform. Additionally, these strands will generally agglomerate into interconnected networks, which show numerous multiple different pores [14]. 


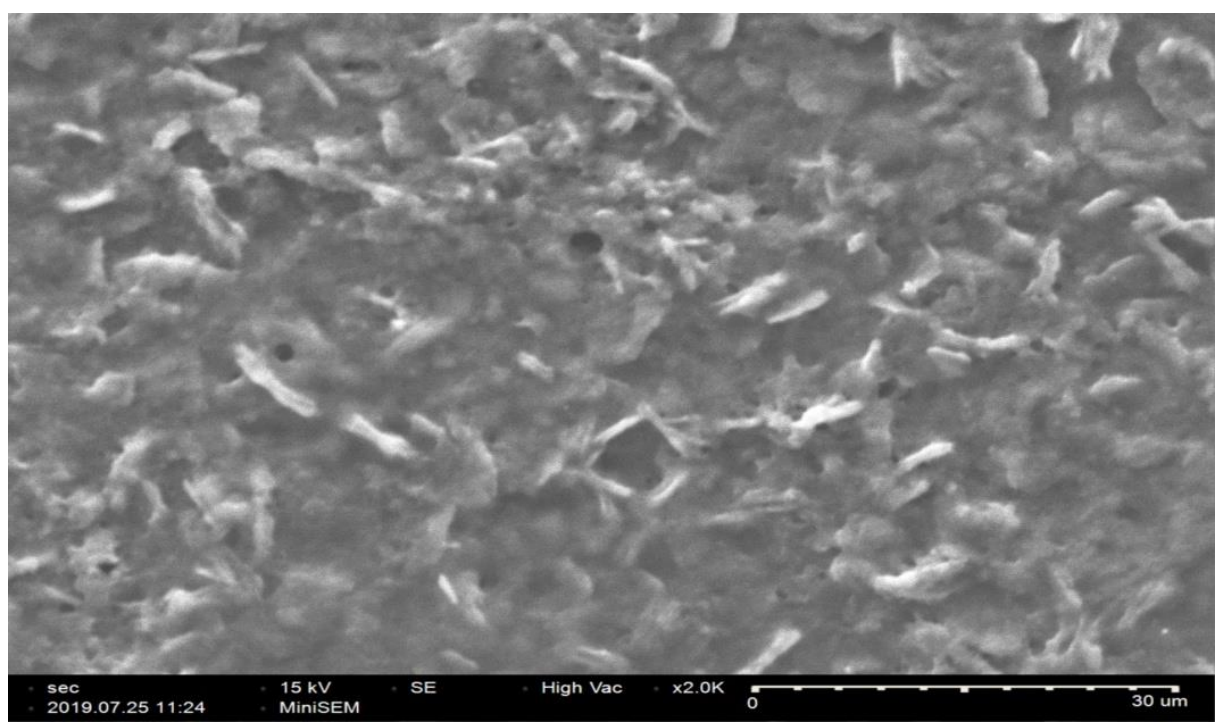

Figure 8. SME images showing a surface morphology of polyaniline (PANI) electrodeposited on a GC substrate.

\subsection{Fourier transforms infrared spectroscopy.}

FTIR spectra of PANI were obtained in the transmission range $400-4000 \mathrm{~cm}^{-1}$, as shown in Figure 9. The characteristic absorption bands for PANI are $592.85 \mathrm{~cm}-1(\mathrm{C}-\mathrm{N}-\mathrm{C}$ bond mode of the aromatic ring), $700.84 \mathrm{~cm}^{-1}$, and $831.98 \mathrm{~cm}^{-1}$ (C-C, $\mathrm{C}-\mathrm{H}$ bond mode of the aromatic ring), $1155.97 \mathrm{~cm}^{-1}$ (out-of-plane $\mathrm{C}-\mathrm{H}$ bonding in the benzene ring), $1302.53 \mathrm{~cm}^{-1}$ (S Q O bonding for camphosulfonic acid), $1503.09 \mathrm{~cm}^{-1}$ (C-N stretching of the benzene ring), 1572.52 $\mathrm{cm}^{-1}$ (C Q N stretching of the quinoid ring), and $3500 \mathrm{~cm}^{-1}-\mathrm{CH}$ combinations and indicates secondary amines [15-18].

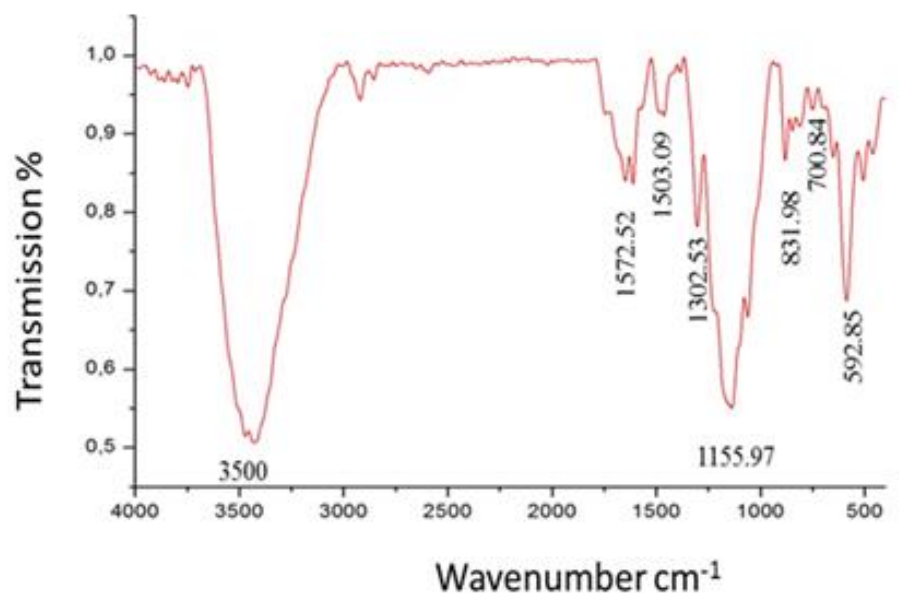

Figure 9. FTIR spectrum of the PANI thin film.

\subsection{Raman spectroscopy.}

The Raman spectrum of polyaniline is the superposition of the spectra of the aniline monomers, as well as the additional lines coming from the formation of the $\mathrm{C}=\mathrm{N}-\mathrm{C}$ imine bonds and the C-NH-C amine bonds between the quinoid rings, the less intense peaks, are due to the intrachain and interchain dipolar interactions which modify the polarizability of the chains and tend to orient them perpendicularly to the Pt anode as well as to the electric field lines of the incident radiation. The important region of the polyaniline spectrum is located between $1100 \mathrm{~cm}^{-1}$ and $1700 \mathrm{~cm}^{-1}$; in which we find all the bands representing the modes of vibration 
characteristic of the polyaniline, for the base form pernigraniline, we observe the following bands: $1157 \mathrm{~cm}^{-1}$ corresponding to the deformation vibration of the $\mathrm{C}-\mathrm{H}$ bond in the quinoid rings, $1215 \mathrm{~cm}^{-1}$ characterizing the elongation vibration of the $\mathrm{C}-\mathrm{N}$ bond, 1330 polaronic conduction, $1480 \mathrm{~cm}^{-1}$ corresponding to the elongation vibration of the $\mathrm{C}=\mathrm{N}$ bond, $1555 \mathrm{~cm}^{-1}$ corresponding to the elongation vibration of the $\mathrm{C}-\mathrm{C}$ bond, $1579 \mathrm{~cm}^{-1}$, elongation vibration of the $\mathrm{C}=\mathrm{C}$ bond in the quinoid rings, 1606 corresponding to the deformation vibration of the $\mathrm{C}$ $\mathrm{C}$ bond and the two bands of weak intensities $2923 \mathrm{~cm}^{-1}$ and $3025 \mathrm{~cm}^{-1}$ corresponding to the vibrations of the $\mathrm{C}-\mathrm{H}$ and $\mathrm{C}-\mathrm{H}$ bonds [19-21].

The intensity of the lines increases with the polarizability of the chains, which in turn increases with the length and structure of the chains. The peak of position $697.23 \mathrm{~cm}^{-1}$ and intensity 6.487 is located in the microwave domain. Its high intensity corresponds to a strong polarization of the polyaniline chains due to the increase of their polarizabilities as well as the rotation around the imine and amine bonds, which results in the deformation of the chains due to the inter-chain dipole-dipole interactions as well as the inter-chain interactions which entail the winding of the chains and their organization in an ordered structure.

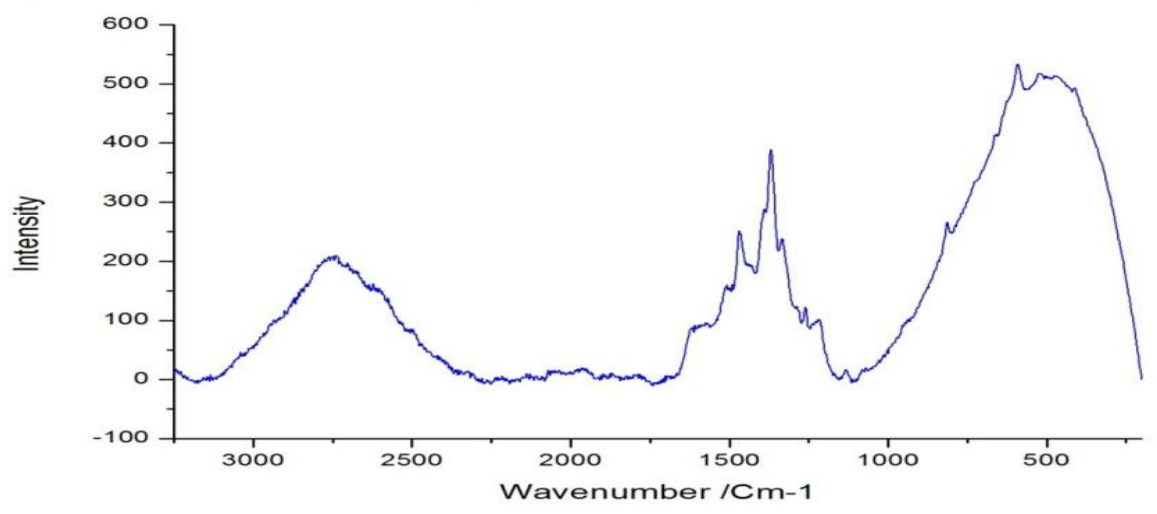

Figure 10. Experimental Raman spectrum for polyaniline.

\subsection{X-ray diffraction.}

$\mathrm{XRD}$ is employed for the assurance of the crystallinity degree of polymeric compounds. Crystalline orientation of conducting compound is extremely attention-grabbing, as a result of an additional highly-ordered system may show an aluminiferous property like conducting state, but the crystallinity of polyaniline and also the intensity of peaks rely on the synthesis conditions-polyanilines square measure semi-crystalline in nature and a 2-phase system. The innovation that the compound chains squared measure parallel and ordered in shut packed array is that the crystallites region, whereas the section where the chains are not ordered and do not have parallel alignment, is the amorphous region. The quicker full-grown of the chemical compound ends up in disorder orientation of chemical compound chains and amorphous polymer structure.

Figure 11 shows XRD patterns of PAni. The crystallin PAni shows two characteristic peaks of the emeraldine salt sort of PANI were indexed at $2 \Theta=30$ and $41^{\circ}$. These peaks area unit attributed to the parallel and perpendicular periodicity of the polymer chains [22-28]. The presence of an amorphous phase makes it a semi-crystalline polymer. 


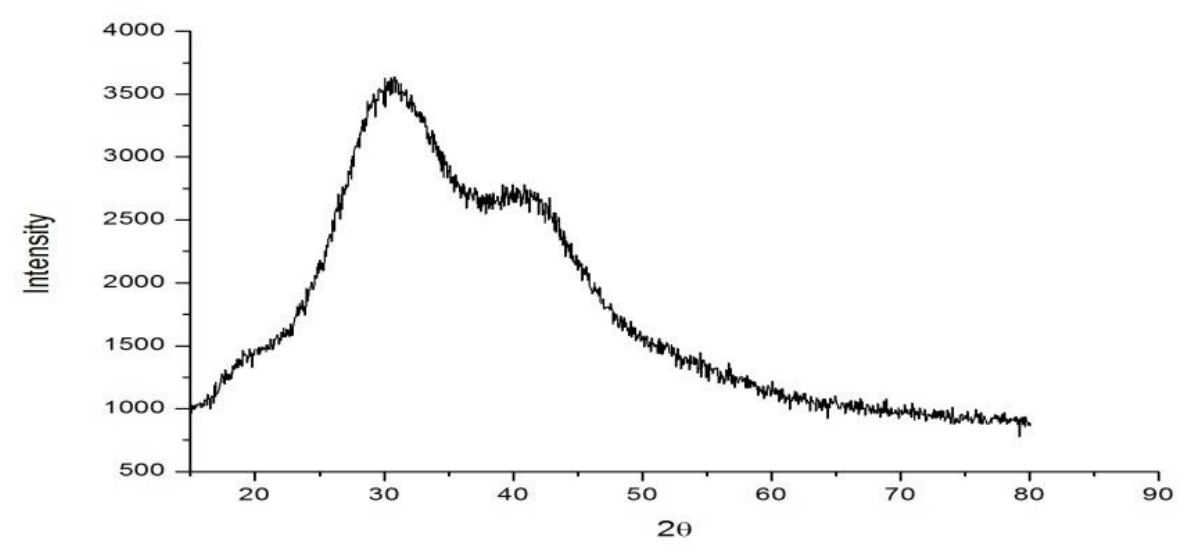

Figure 11. XRD of polyaniline.

\section{Conclusions}

We have synthesized polyaniline by electrochemical polymerization method from liquid aniline monomer. The formation of PANI was confirmed by Voltammetric studies, XRD, Raman spectroscopy, FTIR, and SEM. XRD studies revealed that the PANI film deposited on a glassy carbon substrate is polycrystalline. Proper formation of the Polyaniline film in a conducting form was established by FTIR measurement and Raman spectroscopy. The morphology shows the presence of fibers in the polymeric structure. The greatest advantage of conductive polymers is their vast versatility.

The key to this is the dopant. The alternative of dopant defines the properties of the compound and permits its functionalization for a specific application. The dopants are often expelled and incorporated once more into the compound, permitting the management of these planned physical properties if the chosen bio-molecule cannot be used because the dopant will still be incorporated victimization associate intermediating doping molecule. Suppose doping is not the proper way to build the conductive compound suited for the associate application, physical adsorption, defense, and valency bonding supply different routes.

\section{Funding}

This research received no external funding.

\section{Acknowledgments}

The authors want to thank the professors and Ph.D. students in the laboratory of Physical Chemistry of Materials, FSBM, Hassan II University of Casablanca, Morocco, for the support needed to carry out this work.

\section{Conflicts of Interest}

The authors declare no conflict of interest.

\section{References}

1. Kamarudin, S.; Rani, M. S. A. B. A.; Mohammad, M.; Mohammed, N. H.; Su'ait, M. S.; Ibrahim, M. A.; Razali, H. Investigation on size and conductivity of polyaniline nanofibersynthesised by surfactant-free polymerization.J Mater Res Technol 2021, 14, 255-261,https://doi.org/10.1016/j.jmrt.2021.06.057. 
2. Tarawneh, M. A. A.; Saraireh, S. A.; Chen, R. S.; Ahmad, S. H.; Al-Tarawni, M. A. M.; Al-Tweissi, M.; Yu, L. J. Mechanical, thermal, and conductivity performances of novel thermoplastic natural rubber/graphene nanoplates/polyaniline composites. $J$ Appl Polym Sci2020, 137, 48873,https://doi.org/10.1002/app.48873.

3. Kamarudin, S.; Rahman, Z. A. A.; Rani, M. S. A.; Mohammad, M.; Mohammed, N.; \& Yaakob, Z. Acrylic acid-grafted polyaniline fibers for nickel ion removal from water: synthesis, characterization and adsorption kinetics. Polym Bull2021, 1-13. https://doi.org/10.1007/s00289-021-03585-1.

4. Elhalawany, N.; Elmelegy, H.; Nayfeh, M. Synthesis, characterization and electrical properties of highly conductive polyaniline/gold and/or platinum nanocomposites. Synth Met2015, 205, 145152,https://doi.org/10.1016/j.synthmet.2015.04.004.

5. Madaswamy, S. L.; Alothman, A. A.; AL-Anazy, M.; Ifseisi, A. A.; Alqahtani, K. N.; Natarajan, S. K.; Angaiah, S,; Dhanusuraman, R. Polyaniline-based nanocomposites for direct methanol fuel cells (DMFCs) - A Recent Review.J Ind Eng Chem 2021, 97, 79-94,https://doi.org/10.1016/j.jiec.2021.02.008.

6. Shawai, A. S.; Essa, A. F.Preparation and study of the structural and optical properties for polyaniline/Cu nanocomposite. Mater. Today2021, 45, 5804-5808,https://doi.org/10.1016/j.matpr.2021.03.171.

7. Hamham, S.; Cherqaoui, A.; Belaaouad, S.; Naimi, Y.Organic Semiconductivity and Photovoltaism: Concepts and applications, Mediterr.J.Chem., 2019, 9, 65-77, https://doi.org/10.13171/mjc91190820600sh.

8. Toušek, J.; Rutsch, R.; Toušková, J. Explanation of the high conductivity of $\mathrm{HCl}$ protonated polyaniline films,Mater. Chem. Phys2021,260, 124-153,https://doi.org/10.1016/j.matchemphys.2020.124153.

9. Tran, T. K. ; Kim, N. ; Le, Q. C. ; Nguyen, M. T. ; Leu, H. J. ; Thi, K. N. V. Electrochemical preparation and characterization of polyaniline enhanced electrodes: An application for the removal of cadmium metals in industrial wastewater.Mater. Chem. $\quad$ Phys2021,261, 221,https://doi.org/10.1016/j.matchemphys.2021.124221.

10. Saouti, F. ; Charquaoui, A. ; Naimi, Y. Physico-chemical factors conditioning the electronic conduction of conductive polymers. E3S Web Conf 2021 , 229, 01058, https://doi.org/10.1051/e3sconf/202122901058.

11. Wang, T.; Sun, H.; Peng, T.; Liu, B.; Hou, Y.; Lei, B. Preparation and characterization of polyaniline/pphenylenediamine grafted graphene oxide composites for supercapacitors. J. Mol. Struct2020, 1221, 128835,https://doi.org/10.1016/j.molstruc.2020.128835.

12. Wu, G.; Li, L.; Li, J. H.; Xu, B. Q. Methanol electrooxidation on Pt particles dispersed into PANI / $\begin{array}{lllll}\text { SWNTcomposite } & \text { films.J. Power } & \text { Sources2006, } & 155, & 118-127,\end{array}$ https://doi.org/10.1016/j.jpowsour.2005.04.035.

13. Mu, S.; Chen, C.; Wang, J. The kinetic behavior for the electrochemical polymerization of aniline in aqueous solution.Synthetic metals, 1997,88, 249-254,https://doi.org/10.1016/S0379-6779(97)03863-0.

14. Antar, A.; Naimi, Y.; Takky, D. Development of nickel-cobalt bimetallic/conducting polymer composite usedas a catalyst in the oxygen evolution reaction. Environ. Earth Sci2018, 161, 012027,https://doi.org/10.1088/1755-1315/161/1/012027.

15. Jamil, S.; Ahmad, Z.; Ali, M.; Khan, S. R.; Ali, S.; Hammami, M. A.;Haroon, M.; Associate, M. R. S. A. J. Synthesis and characterization of polyaniline/nickel oxide composites for fuel additive and dyes reduction. Chem. Phys. Lett2021, 776, 138713,https://doi.org/10.1016/j.cplett.2021.138713.

16. Arora, R. Polyaniline conducting Polymer/Rice husk for chromium adsorbent from wastewater for Environment/Energy $\quad$ management.Mater. Today: $\quad$ Proc2021, $45, \quad$ 5299-5302, https://doi.org/10.1016/j.matpr.2021.01.901.

17. Prabhu, R.; Jeevananda, T.; Reddy, K. R.; Raghu, A. V. Polyaniline-fly ash nanocomposites synthesized via emulsionpolymerization: Physicochemical, thermal and dielectric properties .Mater. Sci. Technol. 2021, 4, 107-112, https://doi.org/10.1016/j.mset.2021.02.001.

18. El Makhloufy, S.; Oubouaza, R.; Ouasri, A.; Belaaouad, S.X-Ray Diffraction and Infrared Spectroscopy Data Review Analyses of the Calcium Phosphates.Biointerface Res. Appl. Chem.2022,12, 732755,https://doi.org/10.33263/BRIAC121.732755.

19. Nascimento, G. M.; Pradie, N. A. Resonance Raman characterization of poly(benzidine) in different oxidation states. J. Mol. Struct.2021, 1242, 130751,https://doi.org/10.1016/j.molstruc.2021.130751.

20. Oubouaza, R.; Benson, M.; Wojciechowski, J.; Chtita, S.; Tridane, M.; Belaaouad, S. Synthesis, Crystal Structure, Vibrational Study and DFT Computation of Barium Dihydrogenomonophosphate $\mathrm{Ba}\left(\mathrm{H}_{2} \mathrm{PO}_{4}\right)_{2}$.Biointerface Res. Appl. Chem. 1133,https://doi.org/10.33263/BRIAC121.11201133.

2022, $12, \quad 1120$

1120


21. Zerraf, S.; Belhabra, M.;Tridane, M.; Belaaouad, S. Chemical Preparation, Thermal Behavior and IR Studies ofthe New Chromium Diphosphate Hydrate and Crystal Structure of its Corresponding Anhydrous.Biointerface Res. $\quad$ Appl. Chem. 2021, $\quad 11, \quad$ 13412-13420, https://doi.org/10.33263/BRIAC115.1341213420.

22. Kadri, Y.; Srasra, E.; Bekri-Abbes, I.; Herrasti, P. Facile and eco-friendly synthesis of polyaniline/ZnO composites for corrosion protection of AA-2024 aluminium alloy.J. Electroanal. Chem. 2021,893, 115335,https://doi.org/10.1016/j.jelechem.2021.115335.

23. Lutukurthi, D. K.; Dutta, S.; Behara, D. K.Effect of ignition temperature and fuel amount on photocatalytic activity of solution combustion synthesized ZnO.Ceram. Int.2020,46, 22419-22428, https://doi.org/10.1016/j.ceramint.2020.05.324.

24. Ene, C. D.; Patrinoiu, G.; Munteanu, C.; Ene, R.; Chifiriuc, M. C.; Carp, O.Multifunctional ZnO materials prepared by a versatile green carbohydrateassisted combustion method for environmental remediation applications.Ceram. Int.2019,45, 2295-2302, https://doi.org/10.1016/j.ceramint.2018.10.144.

25. Zak, A. K.; Abd Majid, W. H.; Wang, H. Z.; Yousefi, R.; Golsheikh, A. M.; Ren, Z. F. Sonochemical synthesis of hierarchical $\mathrm{ZnO}$ nanostructures.Ultrason. Sonochem.2013,20,395400,https://doi.org/10.1016/j.ultsonch.2012.07.001.

26. Khataee, A.; Soltani, R. D. C.; Karimi, A.; Joo, S. W. Sonocatalytic degradation of a textile dye over Gddoped $\mathrm{ZnO}$ nanoparticles synthesized through sonochemical process.Ultrason. Sonochem. 2015,23, 219-230, https://doi.org/10.1016/j.ultsonch.2014.08.023.

27. Potdar, S. B.; Praveen, B. V. S.; Sonawane, S. H. Sonochemical approach for synthesis of zinc oxide-poly methyl methacrylate hybrid nanoparticles and its application in corrosion inhibition.Ultrason. Sonochem. 2020,68, 105-200, https://doi.org/10.1016/j.ultsonch.2020.105200.

28. Rayathulhan, R.; Sodipo, B. K.; Aziz, A. A. Nucleation and growth of zinc oxide nanorods directly on metal wire by sonochemical method.Ultrason. Sonochem. 2017,35,270-275, https://doi.org/10.1016/j.ultsonch.2016.10.002. 